\title{
RECENT DEVELOPMENTS IN EARTHQUAKE HAZARD MITIGATION IN THE UNITED STATES
}

\author{
W. T. Holmes ${ }^{1}$
}

This paper was the keynote address at the 1996 Annual Conference of the Society.

\begin{abstract}
SUMMARY
Recent research and development projects in the United States that could significantly affect the future mitigation of seismic risk are summarized. Specific activities described include a report to the governor of California on the Northridge earthquake, the ongoing effort to develop a new national seismic zoning map, development of a comprehensive regional seismic loss estimation methodology, and development of guidelines for the seismic rehabilitation of buildings. Interest in performance based seismic design is discussed and several new large-scale mitigation programs are described.
\end{abstract}

\section{INTRODUCTION}

There is considerable activity aimed at improving codes, standards, mitigation techniques, and general preparedness for earthquake events in the United States, despite the continuation of a nominal spending level by the federal government for seismic research. This paper is not intended to be a comprehensive survey of work in all earthquake disciplines, but rather a snapshot of progress as represented by several significant activities, primarily in the areas associated with building design and retrofit.

Four specific projects are covered:

1) the report to the governor of California following the Northridge earthquake recommending improvements in policy,

2) Project 97, the effort to create a new national seismic zone map,

3) the development of a comprehensive, standardized method to estimate regional losses from earthquakes, and

4) a major effort to develop guidelines for seismic retrofit of existing buildings.

In addition, a discussion is included on progress toward performance based seismic design as represented by several different developmental projects. Finally, several specific examples of mitigation programs are described.

The earthquake engineering community in the United States is large and complex. A glossary of acronyms, agencies, organizations, and programs is given at this end of this paper to avoid the necessity of undue explanation within the text. Agencies or projects in the field of earthquake engineering that are not related to discussions in this paper may be not included. Credits to the large number of people who have contributed to the projects described are also included in the glossary. The first time that a term included in the glossary is used in the text, it is designated by an asterisk.

1 Structural Engineer, Vice President, Rutherford and Chekene, San Francisco, CA, USA and 1996 NZNSEE Travelling Lecturer

\section{THE REPORT TO THE GOVERNOR ON THE NORTHRIDGE EARTHQUAKE}

On March 1, 1994, Governor Pete Wilson of California issued an executive order instructing the California Seismic Safety Commission (SSC) ${ }^{*}$ to review the effects of the Northridge earthquake and to coordinate a study of the specific policy implications, with particular attention to seismic structural safety and land-use planning. The SSC authorized studies comprising four subject areas: geotechnical, lifelines, buildings, and land-use planning. The Commission then used these studies [1], along with considerable direct testimony previously received on the results of the earthquake, to author the final report to the Governor. The Northridge Earthquake: Turning Loss to Gain [2]. The report includes 157 specific recommendations, but concludes in summary that to. reduce the earthquake risk in California,

...government agencies, businesses, and private individuals must be made accountable for managing their earthquake risks to achieve four basic goals:

- Make seismic safety a priority...

- Improve the quality of construction...

- Reduce the risk from seismically vulnerable structures ...

- Improve the performance of lifelines...

Those four goals can be reached by implementing the Commission's recommendations. Seven broad tasks must be completed to achieve those goals:

- Define acceptable risk...

- Provide incentives for risk reduction...

- Improve the use of earth science knowledge to reduce risk...

- Improve the use of land-use planning to manage seismic risk...

- Improve the code development process...

- Support focused research...

- Improve state-level programs.... [2, pp. xiv-xvi] 
In the area of building design and construction, the report includes 85 specific recommendations including many pertaining to specific California State licensing laws. Laws governing school and hospital construction, and policies and procedures of State agencies. However, in summarizing the recommendations concerning buildings, the report suggests that

...although California has come a long way since the 1971 San Fernando earthquake, there are many improvements that still must be made to ensure that California's economy, as well as its citizens, survive a major urban earthquake:

- The quality of design and construction must be improved...

- Building codes must be improved...

- Nonstructural hazards must be reduced...

- The risk from existing buildings must be reduced... [9. p. xi]

Two major recommendations of the report are already well underway. First, the $\mathrm{SAC}^{*}$ joint venture has been formed in a significant effort to solve many of the problems created by unexpected damage to steel moment frame structures. Secondly, a law has been passed by the state legislature requiring seismic retrofit of older hospitals in California over a 40 -year period. Many of the other recommendations are under consideration by the legislature or state agencies. One particularly interesting recommendation would concentrate the responsibility for development of seismic building $\operatorname{codes}^{*}$ in the state in one agency. It is unclear what impact this would have on the long tradition of code development by volunteers within SEAOC*.

\section{PROJECT $97^{*}$}

To represent varying seismic hazard nationally, the 1994 NEHRP Provisions ${ }^{*}$ [3] use maps that were originally developed for ATC 3-068 [4] in 1970. These maps gave values of $A_{a}$ and $A_{v}$ (peak effective acceleration and velocity coefficients) in contours with $10 \%$ chance of exceedance in 50 years and considerable engineering judgment was used in their development. Not only was no scientific definition given for "effective" peaks, but coefficients were given a ceiling of $0.4 \mathrm{~g}$. Although new probabilistic maps of spectral ordinates subsequently have been developed by USGS ${ }^{*}$, BSSC $^{*}$ has been unable to develop a national consensus for their direct use or to agree on a method to otherwise convert this information to code design values. The primary disagreements were over local details of seismicity and methods to account for the wide range of characteristics of hazard curves found across the U.S.

Project 97 was developed by BSSC to coordinate new national mapping efforts by USGS and development of appropriate seismic design procedures based on the new maps by a special BSSC committee, the Seismic Design Procedures Group (SDPG). Recommendations developed by the SDPG will be made to the normal provisions updating committee and must be folded into their standard updating procedures for the 1997 Provisions. The scientifically based maps from USGS are due in May 1996 and the SDPG will make their final recommendations by August 1996.

Preliminary recommendations of the SDPG include use of spectral value at periods of 0.0 and 1.0 seconds for input into code formulae, consideration of both probabilistic and deterministic maps for design values and, most significantly, adoption of a policy to provide approximately equal margins against collapse for large, rare events (taken as $2 \%$ exceedance in 50 years or equivalent).
To implement these policies, the SDPG defined four significantly different types of seismic threats:

1) Regions of high seismicity near known faults,

2) Regions of high/moderate seismicity where fault sources are not well defined,

3) Regions of low seismicity,

4) Regions of negligible seismicity.

This is shown schematically in Figure 1, using distance from a known fault to designate the different regions. The dotted line represents the typical characteristics of relatively infrequent probabilistic motions.

Starting at great distance from known seismicity (on the right of Figure 1), a region is defined where no seismic design is required (the 0 region). Next, moving to the left, in areas where sources are undefined but there is known seismicity, the probabilistic value of motion at any site is extremely low, but in the direct area of an event (Magnitude 5.5-6.0), meaningful seismic design would be required to prevent serious damage. In this region a minimum level of seismic design should be required but since this design level is above the probabilistic mapped value, the region is termed, Deterministic Floor (DF). Most of the country would be in a region where probabilistic values, as have traditionally been used, would be appropriate and this region would be termed Probabilistic $(P)$. However, in regions very close $(15 \mathrm{~km})$ to faults, particularly multiple faults, combined probabilities and the large variability of near field attenuation relationships create unreasonably high ground motion values using standard probabilistic methods. Mean deterministic values would be used in these regions, which would be termed Deterministic Ceiling (DC).

The "rules" tentatively established to create design maps from the USGS hazard maps are shown in Table 1.

The SDPG also recognized that code detailing requirements must be revised to be consistent with the premise of the new maps. This consists primarily of "undoing" certain requirements installed to compensate for perceived weaknesses in the old maps. For example, force reduction factors can be made consistent for a given structural system throughout the country because of the more consistent basis of the maps. In areas of no-design, it is being proposed to strengthen prescriptive provisions intended to assure structural stability and prevent progressive collapse. In the near field represented by Region DC, it is proposed to prohibit construction of buildings with poor configurations and require consideration of large motions for all buildings over five stories.

\section{NIBS NATIONAL EARTHQUAKE LOSS ESTIMATION METHODOLOGY*}

NIBS ${ }^{*}$ is developing for FEMA* a nationally applicable standardized methodology tor estimating potential earthquake losses on 3 regional basis. The goal is to enable creation of consistent and affordable earthquake loss estimates to be used by local agencies tor planning and stimulating mitigation efforts, and preparing tor emergency response and recovery following an earthquake. Standardization will also allow the estimates to be used to assess the nationwide risk of losses from earthquakes and to provide a basis tor allocation of resources for mitigation. The project began in October 1992 and is scheduled for completion in late 1996. It was quickly realized that the calculations used in loss studies lend themselves to computerisation, particularly GIS-based systems, and the project is now concentrated on development of computer software, 


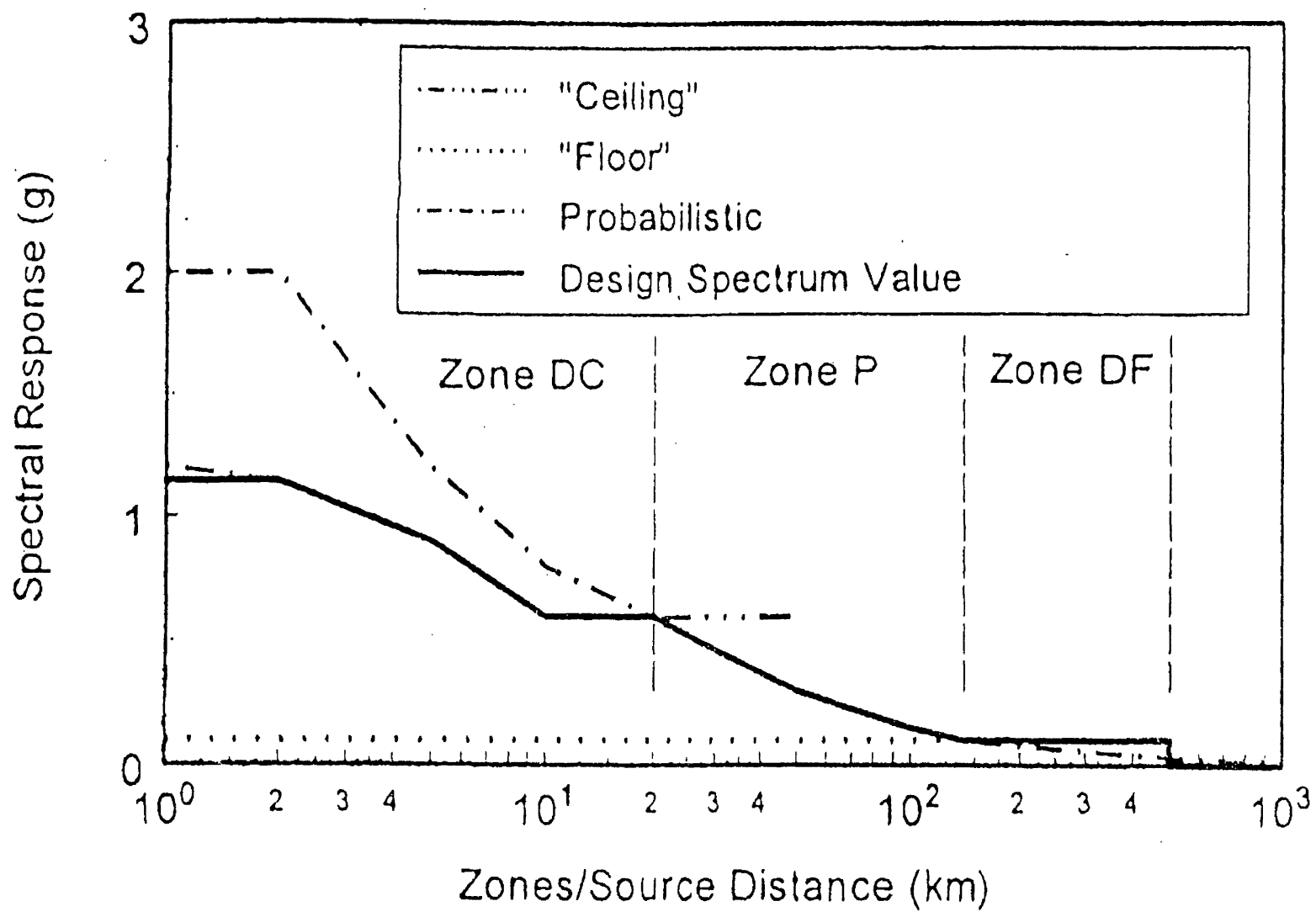

FIGURE 1. Schematic of different seismic regions (source - C Kircher, SDPG)

Table 1. Rules to create design values map from hazard maps

\begin{tabular}{||l||l||}
\hline \hline Region & Rules \\
\hline \hline 0 & $\begin{array}{l}\text { Draft position is to establish Region } 0 \text { based on the } 2 \% / 50 \text { year event for poor } \\
\text { soil using a life-safety threshold spectrum of } \mathrm{S}_{\mathrm{a}(0.3)}=0.25 \mathrm{~g} \text { and } \mathrm{S}_{\mathrm{a}(1.0)}=0.10 \mathrm{~g} . \\
\text { Areas with hazard below this should be in Region } 0 .\end{array}$ \\
\hline 0-DF & $\begin{array}{l}\text { Soft Border between DF and 0: Areas where spectral values on soft rock (the } \\
\text { map basis) fall below a life safety threshold spectrum but site soil amplification } \\
\text { factors push values above this spectrum. Sites above this limit would require } \\
\text { seismic design similar to the DF Region. }\end{array}$ \\
\hline DF & $\begin{array}{l}\text { A minimum design value larger than the threshold spectrum (1.33x is proposed). } \\
\text { This minimum should govern until the values mapped in Region P became larger. }\end{array}$ \\
\hline P & $\begin{array}{l}\text { Maximum capable earthquake is estimated as the } 2 \% \text { / 50 year earthquake as } \\
\text { mapped on the probabilistic hazard maps. The design earthquake is being defined } \\
\text { as two-thirds of maximum capable earthquake (based on expected structural } \\
\text { margins against collapse). }\end{array}$ \\
\hline DC & $\begin{array}{l}\text { Deterministic seismic hazard spectral maps are used to determine design } \\
\text { earthquake motion. Magnitude of deterministic earthquakes based on best } \\
\text { estimate of maximum earthquake that each source is capable of producing. } \\
\text { Ground shaking at distance based on median estimate of ground motion } \\
\text { attenuation. Maximum capable earthquake is estimated to be } 1.5 \text { times the design } \\
\text { earthquake (about the same as deterministic maps based on 1 sigma estimate of } \\
\text { ground motion attenuation) }\end{array}$ \\
\hline
\end{tabular}


called HAZUS, encompassing all aspects of the methodology. The methodology is modular, to the extent possible, enabling updating of algorithms or of complete sub-methodologies in any given area.

The methodology is quite comprehensive, considering either specifically or subjectively every loss or planning parameter that may be of interest. The components are shown in Figure 2. The basic geographic unit in the system is a census tract, convenient in the U.S. in terms of size as well as of availability of digitized geometry and data. Given a scenario event, attenuation equations are used to estimate motion in any tract. Inventory is also aggregated by tract, and losses thus estimated. Soils maps can be superimposed to consider site amplification effects, or soil failure. Important individual facilities can also be located. Transportation systems and utility lifelines can also be geometrically modelled and losses estimated.

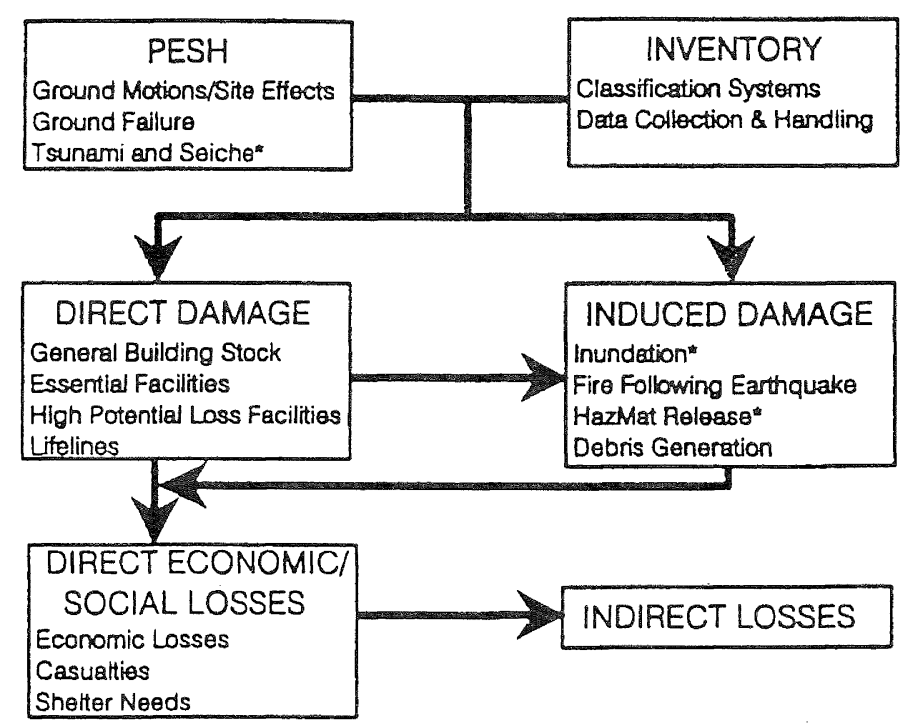

FIGURE 2. Components of earthquake loss study [7]

Information provided includes quantitative estimates of losses in terms of direct costs for repair, loss of function, casualties, loss of residential facilities, and regional economic impacts. Also estimated are loss of function of transportation systems and lifelines and estimated times for restoration. Induced secondary hazards such as fire-following are estimated only in terms of probable extent. Three levels of loss estimates are offered: Level 1, for which the built-in default data bases are used and output is limited in terms of completeness and accuracy; Level 2 , which requires considerable local input of region-specific information such as soils conditions, building and lifeline inventory, but provides more complete and reliable information; Level 3, which combines the most detailed Level 2 data with loss information or fragilities that may be available for specific local facilities.

Estimates of damage to buildings form a significant portion of regional loss studies. In the development of HAZUS, it was concluded that the traditional damage probability matrix parameters - percentage of replacement cost versus shaking intensity - used in ATC 13 [5] and elsewhere, were not sufficiently flexible and needed updating. Parameters are needed that would allow separation of structural and nonstructural damage, that would be adequate measures of casualties, loss of building function, and would improve planners understanding of the likely condition of the community. It was decided that if the building inventory was placed into descriptive damage states, a more realistic picture of postearthquake conditions could be created and improved algorithms for casualties and business interruption could be derived. In addition, spectral ordinates were considered the most flexible and technically accurate measure of shaking characteristics at any site and are used to replace intensity (MMI).

A damage estimating methodology was devised based on a structural response analogy developed over the last 15 years by Freeman and others - the Capacity Spectrum Method [6]. Building types are represented by characteristic nonlinear force deflection curves ("pushover curves"). Response spectra, created by conventional attenuation equations (or otherwise input into the program), are converted to plots of spectral acceleration versus spectral displacement and superimposed on a pushover curve representing a given building type. The intersection of the two curves is taken to represent the seismic displacement demand for that class of structure. Fragility curves for the same class of structure are then used to translate the displacement demand into the probability of reaching the various damage states. The damage states can then be used directly to estimate direct losses, building disruption, and casualties. The method is generally described in Figure 3, taken from documentation in progress [7]. The method offers great flexibility to represent all types of structural behaviour and site-specific response. Initially developed pushover curves and fragilities are being calibrated to match currently available damage data and expert opinion. New building types can be added or adjustments made to representative pushover curves as new data becomes available.

\section{FEMA GUIDELINES FOR SEISMIC REHABILITATION OF BUILDINGS ATC $33^{*}$}

Perhaps the most-far reaching activity intended for general use by practitioners currently in development in the U.S. is the Guidelines and Commentary for Seismic Rehabilitation of Existing Buildings [8], by BSSC, under funding by FEMA. The Guidelines are the culmination of a 10-year FEMA program directed at existing buildings [9]. ATC ${ }^{*}$ is BSSC's subcontractor to develop the Guidelines and the American Society of Civil Engineers is also involved in the 5-year, $\$ 8$ million effort. A $75 \%$ completion draft was published for internal use in December of 1995 and the $100 \%$ draft is due to BSSC in September of 1996. An additional year has been scheduled for review and consensus approval. Many presentations have been given and overview papers already completed on this project [10], including several to be given at the 11 th World Conference in Mexico, so only a broad summary will be given here.

\section{Framework.}

The Guidelines were originally intended for the purposes of design of rehabilitations, but it was quickly recognized that, if an unaltered existing building was put through the analysis and acceptability procedures, the results would represent an evaluation of as-is conditions. Because the methodology is thought to be more reliable and less conservative than other existing methods, it is expected to be widely used for both evaluation and rehabilitation.

The project was ambitious from the start, seeking to incorporate all of the following characteristics: 


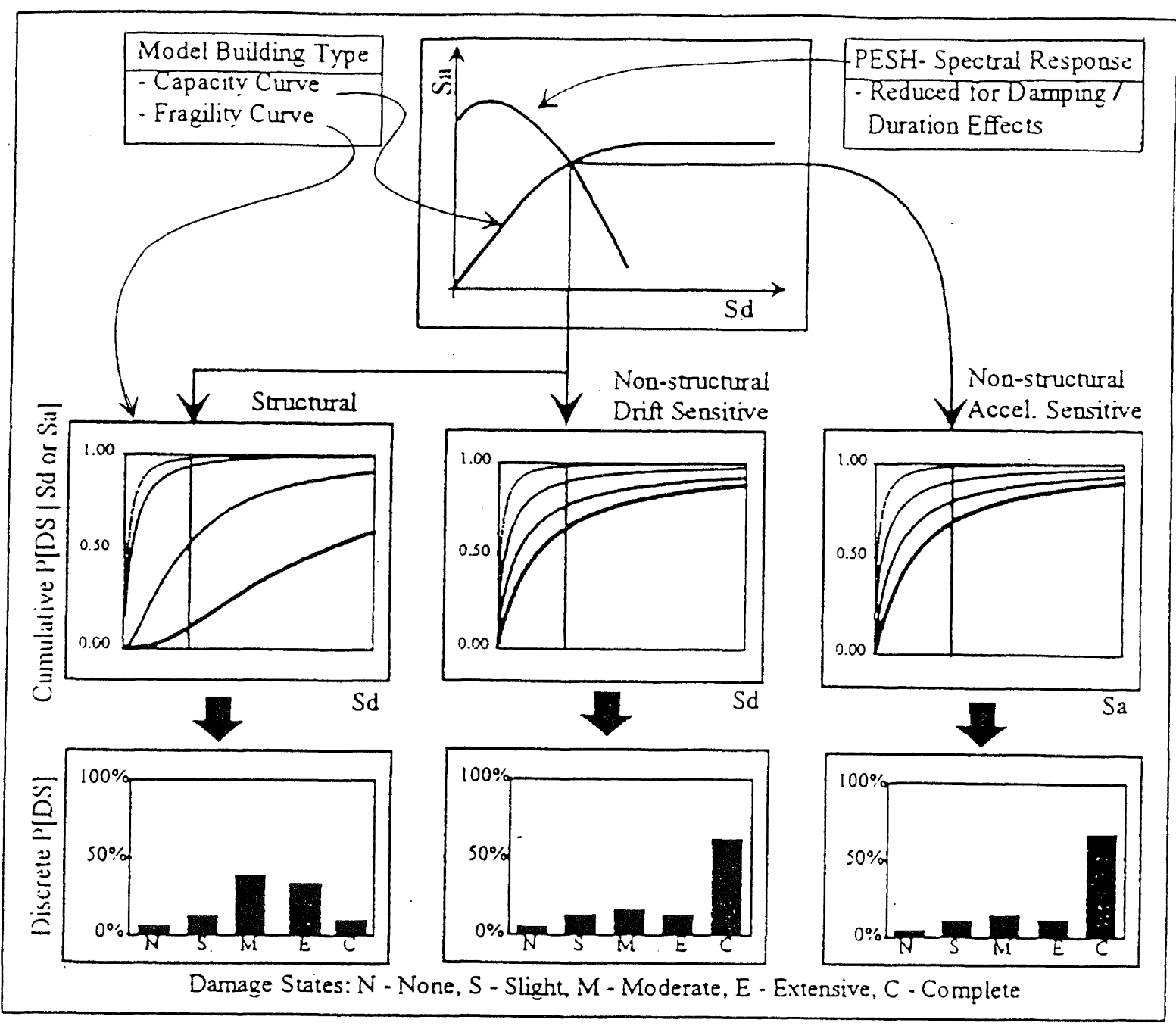

FIGURE 3. Building damage estimation process

- Consider both structural and nonstructural components,

- Explicitly cover most, if not all, structural elements found in existing buildings in the U S., including those of wood, masonry, concrete, steel, and common combinations of these materials.

- Apply in all seismic zones.

- Allow for simple designs where appropriate.

- Provide sufficient guidance to yield consistent results and to be enforceable by building officials.

- Incorporate designs intended for several different levels of seismic performance (performance based design),

- Be adaptable for use either by owners of individual buildings who voluntarily desire to reduce their seismic risk or by local jurisdictions as a required standard in programs that target certain buildings or groups of buildings,

- Cover new technology such as base isolation and the addition of damping devices,

- Allow for easy addition of new test data covering the behaviour of existing components, strengthened components, or new innovative technology,

- Be based on scientific principles such that the dynamic structural response to the shaking and realistic nonlinear material behaviour would not be obscured.
Because of the high economic impact of seismic rehabilitation, the document was not intended to become a national minimum standard or be adopted as a whole into codes, but would be most useful if applicable to the wide variety of current rehabilitation demands in the country. In fact, the need to be performance based stemmed from the wide range of probable applications including, for example, owners who desire certain seismic building performance to protect their business, owners who simply want to reduce their seismic risk within a certain budget, and jurisdictions who want to locally adopt standards to protect the public safety.

The balance between true performance based design in which considerable judgement is exercised by individual engineers, and more prescriptive provisions which are more easily checked by building officials, is a particularly difficult issue in the U.S. Tens of thousands of engineers may be asked to perform seismic rehabilitation across the country, varying from earthquake engineering experts to engineers completely unfamiliar with seismic design. The need to be applicable nationally by engineers of varying skills is clearly important to FEMA's mitigation efforts. Even with this need in mind, a code-like document based on deformations rather than forces and incorporating the basics of capacity design is difficult to keep simple. Concerns already have been expressed by reviewers about the complexity of the proposals and the lack of testing and calibration by trial designs. 
Design flexibility to achieve a wide varies of performance is achieved by specifying the intended performance through a Rehabilitation Objective that consists of 1) a desired damage state (performance level) for 2) a given level of shaking defined probabilistically or deterministically (hazard level). Four Performance Levels are defined and termed, Operational Immediate Occupancy Life Safety and Collapse Prevention, as shown in Figure 4. Any hazard level can be used, but national maps are available for spectral ordinates with $2 \%, 5 \%$, and $10 \%$ chance of exceedance in 50 years and these levels are expected to be commonly used. A smaller serviceability event may also sometimes be considered with a $50 \%$ chance of exceedance in 50 years.

As explained above, the document is intended primarily for local voluntary use. However, in order to set a common national index, a rehabilitation objective called the Basic Safety Objective is specifically defined as performance that meets the Life Safety Performance Level for a ground motion with a $10 \%$ chance of exceedance in 50 years and, in addition, meets the Collapse Prevention Level for a rare, large event (2\% chance of exceedance in 50 years). Interestingly, the primary reason for use of the two level design procedure - concern about performance in the large, rare event - is also driving the design values mapping in Project 97. Coordination of the two projects is underway.

\section{Analysis Methods.}

In order to provide tools for the wide range of probable users of the guidelines, several methods are provided for designing rehabilitation measures. For certain smaller and simpler building types, a Simplified Method is defined. Four Systematic Methods are provided for more general use.

The Simplified Method is based on the same equivalent static force procedures used in U.S. codes for new buildings and is an extension of the FEMA 178 [11] evaluation procedure. In essence, the procedure consists of checking the rehabilitated structure with the FEMA 178 evaluation criteria: When all new, existing, or altered elements meet the criteria, the rehabilitation is considered to meet the Life Safety performance level for the event with a $10 \%$ chance of exceedance in 50 years, for which FEMA 178 was originally developed. The entire suite of Rehabilitation Objectives featured in the balance of the document is not available for the Simplified Method. Since this method is based on a previously developed system for evaluation of buildings, it will not significantly enhance the current evaluation capability.

The Systematic Methods are all based on the deformation demands put on the structure from the seismic motion and therefore represent a significant departure from other U.S. building codes. Use of deformation allows much better evaluation of mixed systems with widely ranging stiffnesses and ductilities, as are commonly found in rehabilitated structures. The methods vary in level of effort and complexity and are termed the Linear Static Procedure (LSP), the Linear Dynamic Procedure (LDP), the Nonlinear Static Procedure (NSP), and the Nonlinear Dynamic Procedure (NDP). The seismic demand used in the Systematic Methods is represented by a response spectrum created from mapped parameters and considering site specific-soil conditions. Since all four methods can be applied to an existing structure with no rehabilitation measures in place, they can be used for evaluation in order to take advantage of the better measures of capacities of elements, as well as to consider rehabilitation objectives other than Life Safety.

\section{Performance Levels and Ranges}

Performance Level: the intended postearthquake condition of a building; a discrete and well-defined point on a scale measuring how much loss is caused by earthquake damage; in addition to casualties, loss may be in terms of property and operational loss.

Performance Range: a range or band of performance, rather than a discrete level.

Rehabilitation Objective: The combination of a Performance Level or Range with Seismic Demand Criteria.

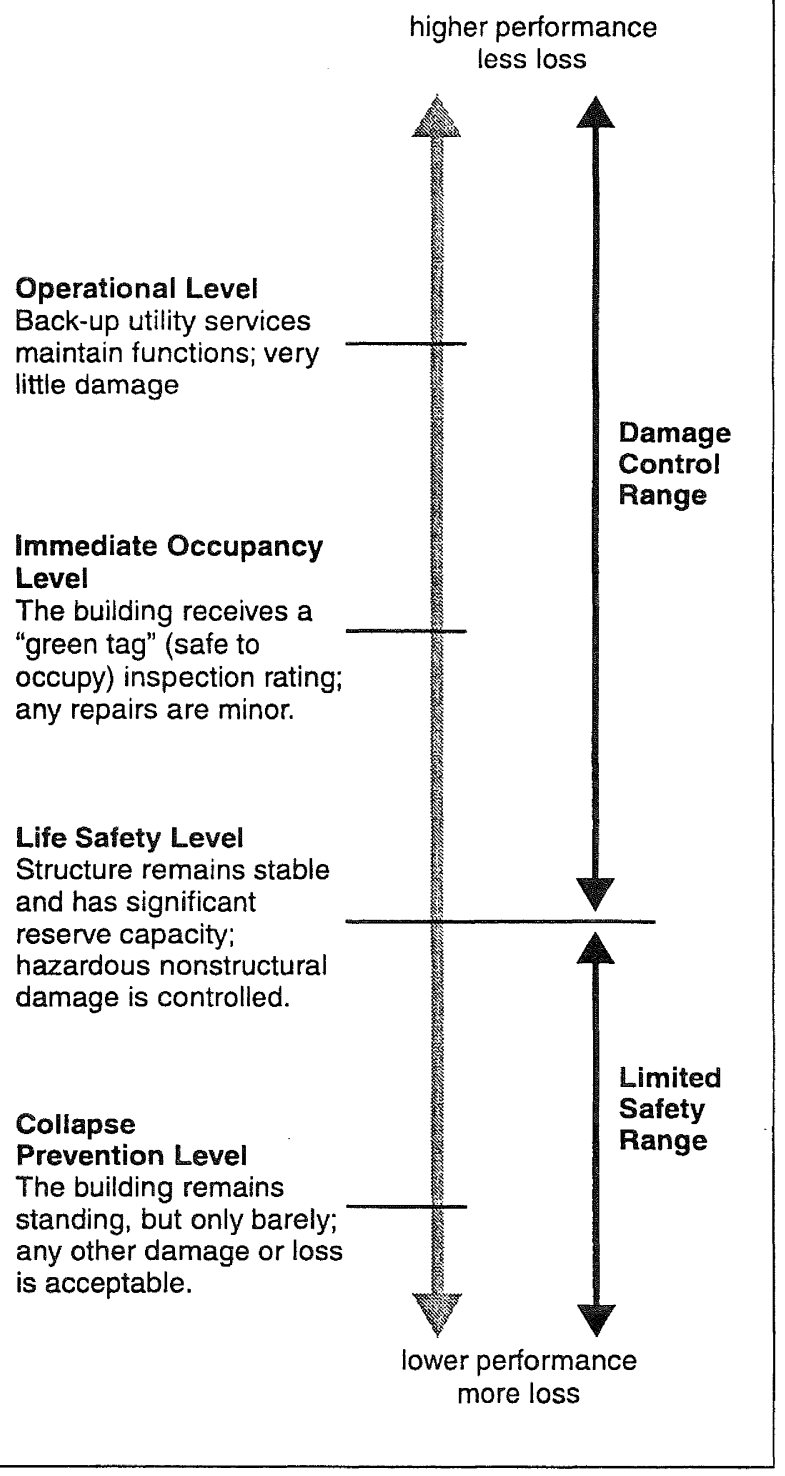

FIGURE 4. Performance levels and ranges [9]

The linear methods are intended to provide an option for practising engineers to use familiar methods, while actually performing analysis and design on a very different basis. Although demand and capacity are specified to measure deformations, appropriately proportional force-related actions, such as axial load, moment, and shear, are used in the analysis and acceptability criteria. Fictitious lateral forces that will 
create a deformed shape appropriate for design purposes are determined by adjusting the calculated elastic deformation response to the probable inelastic deformation response. Coefficients are used for this purpose that consider the period, damping, and hysteretic behaviour of the structure, as shown in Figure 5. Individual structural components are checked for adequacy for either deformation capacity or strength as appropriate. Deformation capacity is given in the document as a multiplier of yield capacities. Specific guidance is given to estimate the maximum force expected on a brittle element, which is to be resisted by capacities determined by traditional yield strength methods. Capacity design or limit state design procedures are encouraged to determine maximum force demand on components. Acceptable component capacities, whether based on deformation or strength, are given for the various performance states for all common materials.

The LSP and LDP are similar in concept, with the LSP using a first mode approximation of the linear response and the LDP being based a conventional linear spectral analysis.

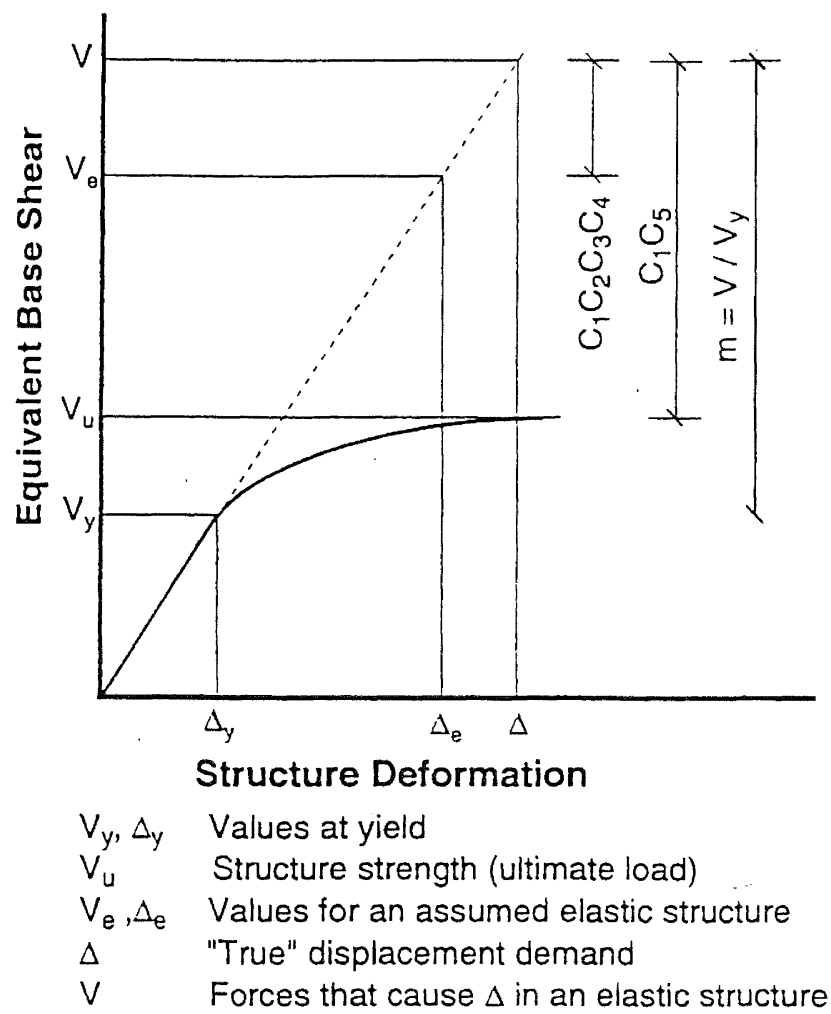

\section{FIGURE 5. Basis for Linear Analysis Procedure [9]}

The NDP represents full nonlinear time history analysis that at the present time is considered overly burdened with assumptions and too time-consuming to be developed into a realistic code-like methodology. However, since realistic structural deformations are being used as the primary analysis parameter in the Guidelines, this procedure can easily be formally integrated when more consensus is reached on models for material behaviour, appropriate representative time histories are developed, and computer programs are developed to make the analysis more practical and consistent.
It is hoped that the NSP will provide a reasonable compromise between the potential inaccuracies of the linear procedures and the impracticality of the NDP. The NSP is based on the development of a "pushover" curve of lateral force versus roof displacement. The pushover curve is developed using a series of static analyses of a structural model that incorporates incremental changes of element stiffness and strength to represent damage (nonlinear computer programs are also used). A displacement demand, estimated by first mode response, is used to define the deformed shape to be used for design, similar to the LSP, but nonlinear behaviour is used to determine the details of the structural deformed shape. Consideration of nonlinear behaviour in development of the pushover curve enables better approximation of local element displacement demands as well as maximum force demands. Although certain limitations of this analytical procedure are recognized, particularly complications from effects of higher mode response, torsion, or the presence of flexible diaphragms, it represents a major improvement over previous methods for most buildings.

\section{Acceptability Criteria.}

Acceptability criteria for structural components have been developed for various performance levels by studying available dynamic test data. Envelopes of hysteretic curves have been created in accordance with pre-established rules and, in general, element behaviour categorized as shown in Figure 6. Strength and deformation capacities have then been established for various performance levels using consistent rules. Direct incorporation of expected cyclic behaviour into the procedure provides a significant advantage over previous evaluation methods in that new test results of existing or altered components can be used immediately. In addition, parameters for untested components can be more easily estimated by comparison with similar assemblies with established values. Similarly, new technologies can be easily integrated into this analysis and acceptability format, reducing the time from development to general use.

\section{PERFORMANCE BASED SEISMIC DESIGN}

Interest from several different sources has recently prompted considerable activity in development of performance based seismic design, including definition of the several levels of performance commonly of interest. The monetary losses and business downtime in the Northridge earthquake created interest in performance better than code mandated life safety at about the same time that the ATC 33 project was facilitating discussion of variable performance demanded by voluntary seismic rehabilitation. A third impetus was SEAOC's ${ }^{*}$ Vision $2000^{*}$ project [12].

Vision 2000 has defined performance levels similar to ATC 33 , but slightly different, demonstrating the difficulty in the U.S. of achieving complete agreement among various groups of experts. A complete spectrum of damage states was defined, ranging from Fully Operational to Collapse. The Vision 2000 damage states are reproduced in Table 2. A scale that includes all damage states rather than only positive performance levels suggests an interesting possibility of standardizing performance based evaluation - evaluating buildings by placing them in a probable damage state. Several multiple building evaluation projects in California have indicated that better consistency among engineers is reached by placing buildings in preset performance categories than by testing compliance with pass-fail criteria. Standardized performance states could be made useful 


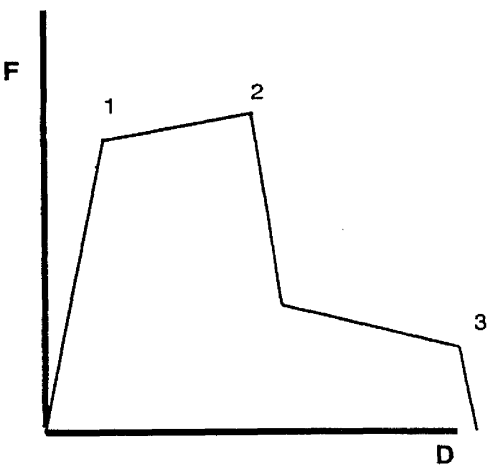

Type 1 Curve

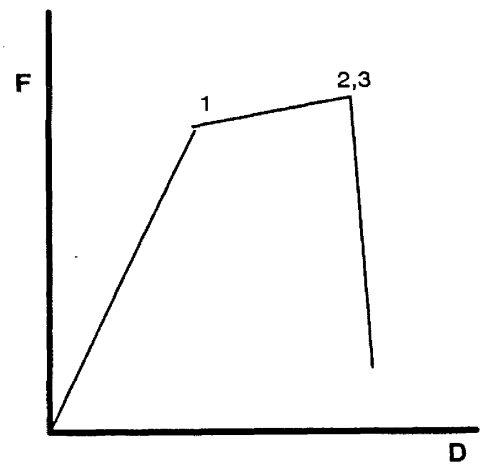

Type 2 Curve

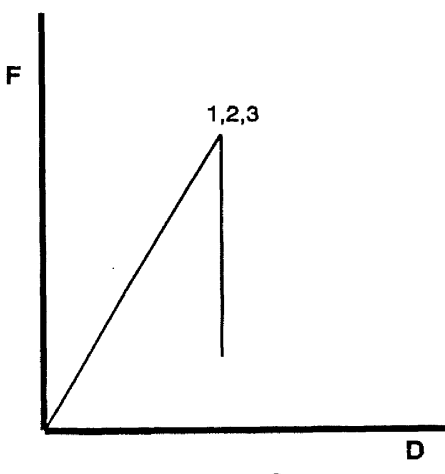

Type 3 Curve

FIGURE 6. General component behaviour curves used in the FEMA guidelines [9]

Table 2. Damage states suggested by Vision 2000 [12]

\begin{tabular}{|c|c|c|c|}
\hline \multicolumn{2}{|c|}{ Damage Rank } & \multirow{2}{*}{ Title } & \multirow{2}{*}{ Notes } \\
\hline Extent & \# & & \\
\hline Negligible & $\begin{array}{l}10 \\
9 \\
\end{array}$ & FULLY OPERATIONAL & $\begin{array}{l}\text { No damage } \\
\text { Negligible structural/nonstructural damage }\end{array}$ \\
\hline Light & $\begin{array}{l}8 \\
7\end{array}$ & OPERATIONAL & $\begin{array}{l}\text { Operational, minor repair } \\
\text { Non-essential operations disrupted }\end{array}$ \\
\hline Moderate & $\begin{array}{l}6 \\
5 \\
\end{array}$ & LIFE SAFE & $\begin{array}{l}\text { Structure is damaged but repairable } \\
\text { Structure is stable. no falling hazards }\end{array}$ \\
\hline Severe & $\begin{array}{l}4 \\
3 \\
\end{array}$ & NEAR COLLAPSE & $\begin{array}{l}\text { Limited egress only } \\
\text { No structural collapse }\end{array}$ \\
\hline Complete & $\begin{array}{l}2 \\
1\end{array}$ & COLLAPSE & $\begin{array}{l}\text { Partial structural collapse } \\
\text { Complete structural collapse }\end{array}$ \\
\hline
\end{tabular}

for owners to judge their risk, prioritize retrofit actions, and possibly assist in setting insurance rates.

In addition to variable performance levels, Vision 2000 has recommended a more holistic approach to seismic design, encouraging involvement from early project concepts through facility maintenance. Particularly emphasized were improved procedures for delivering seismically resistant nonstructural systems.

An interesting refinement in the definition of performance levels has been developed in California's Proposition $122^{*}$ projects. Nonstructural seismic performance is defined separately from structural performance and combined in a matrix form to create a more realistic variety of performance levels. This method allows accurate description of performance levels currently commonly used, particularly in retrofit projects. Table 3 presents this matrix of performances and a discussion of the various combinations follows, generally taken from an intermediate draft of Proposition 122 Product 1.2 [13]. Such a table could be expanded to include the full range of damage states, similar to Vision 2000 , to allow for use in performance based evaluation.

Overall performance level $1 \mathrm{~A}$ : This is the performance level related to functionality. The building structural elements, nonstructural systems, and lifelines are expected to be only minimally damaged or backed-up in such a way as to allow nearly undiminished use of the building. Building contents may also be protected to avoid damage or disruption.

Overall performance level 1B: This is currently the most widely used level in California for critical facilities. The spaces and systems are presumed reasonably useable, but continuity of lifeline service (other than emergency power), either primary or backup, is often not provided. Contents are not fully protected.

Overall performance level $1 \mathrm{C}$ : The combination might represent the desire to avoid a red tag structurally, but to accept considerable clean up before the space is fully useable. It is 
Table 3. Matrix of structural and nonstructural performance levels

\begin{tabular}{||l||c|c|c|c||}
\hline \multicolumn{5}{|c|}{ Combined Performance Levels } \\
\hline \hline \multirow{2}{*}{$\begin{array}{l}\text { Nonstructural } \\
\text { Performance Level }\end{array}$} & $\begin{array}{c}\text { Structural Performance Level } \\
\text { Occupancy }\end{array}$ & $\begin{array}{c}\text { 2. Damage } \\
\text { Control Range }\end{array}$ & 3. Life Safety & $\begin{array}{c}\text { 4. Structural } \\
\text { Stability }\end{array}$ \\
\cline { 2 - 6 } A. Operational & 1A & $*$ & $*$ & $*$ \\
\hline B. Minimal Disruption & 1B & 2B & $*$ & $*$ \\
\hline C. Life Safety & 1C & 2C & $3 \mathrm{C}$ & $*$ \\
\hline D. Hazards Reduced & $*$ & $*$ & $3 \mathrm{D}$ & $*$ \\
\hline F. Not considered & $*$ & $*$ & $*$ & $4 \mathrm{~F}$ \\
\hline \hline
\end{tabular}

* These combinations not normally used.

unlikely that structural level 10 would be combined with less than nonstructural level $\mathrm{C}$.

Overall performance levels 2B, 2C: Within the broad structural performance range of Damage Control, an equally wide range of nonstructural protection might be appropriate. It is unlikely, but possible, to find it desirable to combine structural level Damage Control, with even less thorough nonstructural protection than level C. Specific structural or nonstructural acceptance criteria are difficult to define for these levels, but can be assumed to be between $1 \mathrm{~B}$ and $3 \mathrm{C}$.

Overall performance level 3C: This level is intended to accomplish complete life safety protection, including consideration of all nonstructural components that could be falling hazards.

Overall performance level 3D: This represents the current de facto Life Safety level and probably the most widely used combined performance level in the U.S. The structure is made to conform with one of many so-called structural life safety standards, including consideration of major falling hazards such as parapets, masonry exterior walls and partitions, and cladding. The structural damage level is intended to have a margin of safety before becoming near collapse. Complete mitigation of all nonstructural components that could be life safety hazards, such as is implied by most evaluation "standards", is not included.

Overall performance level 4F: Minimal prevention of structural collapse. By definition, nonstructural protection is not a concern.

\section{MAJOR EFFORTS IN RISK REDUCTION}

California Hospitals. The California state legislature, noting that many hospitals were severely disrupted and several nonfunctional following the Northridge earthquake, passed a law (Senate Bill 1953) requiring gradual retroactive compliance with the state's strict regulations for new hospitals. Buildings judged to represent a structural life safety hazard can not be used for hospital functions after the year 2008. These buildings must be demolished, used for other purposes, or retrofitted. Buildings that don't represent a collapse hazard, but that may not be functional after a major event, must be in substantial compliance with standards for new buildings by the year 2030 . Nonstructural deficiencies that may create a threat to life safety or to important functional capabilities are scheduled to be mitigated incrementally over a 10-15-year period starting about the year 2000. Regulations to implement these requirements are scheduled to be adopted by July of 1997 .

California Bridges. The California Department of Transportation (CALTRANS) continues to retrofit the state's highway bridges of the 94,000 state highway and local bridges in the state, 2000 have been determined to require detailed evaluation and retrofit, at a total estimated cost of $\$ 2,420$ million. Retrofit construction on single-column-pier bridges is nearly complete, but multi-column-pier bridges are less than $10 \%$ complete. Essentially no work has been done on the toll bridges, originally estimated at $\$ 650$ million [1]. However, in February 1996, CALTRANS announced that the original estimate for the San Francisco Bay Bridge was being revised upward from $\$ 300-400$ million to over $\$ 1,000$ million. The total cost of retrofit of these major toll bridges to a reliable functional performance level may eventually prove to be unaffordable.

Federal Buildings. The U.S. Federal government owns nearly 500,000 buildings and about 183,000 of them, containing over 100 million square meters of area, are located where seismic vulnerability is a concern. After successfully putting in place a policy to design all new Federal buildings in accordance with seismic requirements in 1989 [14], the ICSSC $^{*}$ has worked to develop a policy on existing buildings. Standards for evaluation and acceptance of existing buildings have recently been published, known as RP 4 [15]. Although this standard does not incorporate a retroactive program that requires retrofit, controls are in place intended to prevent the current total risk from this building inventory from growing:

1) newly constructed buildings are designed for seismic loading,

2) newly acquired buildings must be evaluated, with serious risks mitigated, and

3) an action which potentially increases the risk will also trigger an evaluation and possible mitigation (change in occupancy, structural modifications, etc.). 
In addition, in preparation for development of a program to require selective retroactivity, all Federal agencies have been instructed, through Executive Order 12941, to prepare estimates of the cost of bringing their inventory into compliance with RP 4. Another ICSSC document, RP 5 [16], has been issued to give guidance and standards for this monumental task.

City of Los Angeles. The City of Los Angeles was the jurisdiction most greatly affected by the Northridge earthquake. The City formed a Task Force to study the damage to buildings and to make recommendations for improvement [17]. In addition to recommending several specific changes in the code for new buildings and as well as some procedural changes in the building department to improve plan checking and inspection, recommendations were made to begin retrofit programs for several building types. The buildings targeted were tilt-up industrial-type buildings, older non-ductile concrete buildings, soft-story wood frame apartment buildings, and private residences on hillside lots. The City Council passed a previously prepared ordinance on tilt-ups shortly after the earthquake and is currently debating the cost and advisability of programs for the other building types. With programs on URMs and tilt-ups firmly in place and seriously considering other building types, Los Angeles continues to provide an impressive example of active seismic risk mitigation.

\section{USA SEISMIC MITIGATION GLOSSARY}

The following descriptions have been informally developed by the author to facilitate general understanding of the meaning of certain acronyms and relationships between documents or organizations. The descriptions have not been reviewed by the governing organizations. The author regrets any inadvertent errors that may have been made in the details, such as funding sources, content of publications, and goals and missions of organizations.

ATC: The Applied Technology Council. A nonprofit corporation established in 1971 through the efforts of SEAOC. ATC is guided by a Board of Directors that now has wide representation from across the country. The purpose of ATC is to assist the design practitioner in structural engineering in the task of keeping abreast of and effectively using technological developments. Project management and administration are carried out by a full-time staff. Project work is conducted by a wide range of highly qualified consulting professionals. Funding for ATC projects is obtained from government agencies and from the private sector.

ATC 3-06: ATC's 1978 publication. Tentative Provisions for the Development of Seismic Regulations for Buildings. The results of a multi year study by a large team of engineers and researchers from around the country to develop new, more comprehensive and nationally applicable provisions for the seismic design of new buildings. The project was sponsored by several federal agencies. See also NEHRP Provisions.

ATC 33: ATC's portion of the FEMA-funded project to develop Guidelines and Commentary for the Seismic Rehabilitation of Buildings (also known as FEMA Guidelines). The project is a 5 year, $\$ 8$ million effort, with BSSC as the prime contractor to FEMA, with ATC and ASCE as subcontractors. ATC is responsible tor developing the Guidelines themselves and ASCE's primary role is to provide input from potential users (by running workshops) and to provide ancillary technical support. ATC has assembled a team of 20-60 engineers and researchers from around the country to develop the initial provisions, scheduled for completion in July 1996. BSSC will then put the document through its internal consensus approval procedure, and intends to publish the completed documents in September 1997. The project has been compared to ATC 3-06 for new buildings.

Credits:

Principal Investigator: C. Rojahn;

Project Director: D Shapiro:

Senior Technical Committee: L. Reaveley, W. Holmes, J. Moehle, T. Atkinson:

Team Leaders: R. Hamburger, M. Mehrain, J. Keaton, C. Arnold, L. Reaveley, D. Foutch, D. Abrams, J. Coil, C. Kircher, C. Poland.

BSSC: The Building Seismic Safety Council. The BSSC was formed to provide a forum to resolve technical and socio-economic issues created by the publication of ATC 3-06. BSSC is made up of representatives of professional and industrial organizations and is funded by FEMA through NIBS. After several years of testing and editing ATC 3-06, BSSC published the first NEHRP Provisions in 1985 and established the Provisions Update Committee (PUC) to triennially update the publication. The recommendations of the PUC are put through an internal consensus process using the member organizations. The PUC receives staff support and travel expenses from BSSC.

Building Codes: There are three model codes available in the U.S.: the Uniform Building Code (UBC), published by the International Conference of Building Officials; the Standard Building Code (SBC), published by the Southern Building Code Congress International (SBCCI); and the National Code, published by the Building Officials and Code Administrators International (BOCA). States and/or local jurisdictions generally adopt one of the model codes, sometimes with and sometimes without modification. The UBC is widely used in the highly seismic west. The seismic provisions of the UBC are based on the recommendations in the SEAOC Bluebook, while the other two are based on the NEHRP Provisions. See also IBC.

CUREe: California Universities for Research in Earthquake Engineering. Composed of representatives of eight major universities in California, CUREe was formed to coordinate and enhance their joint effort in earthquake engineering.

EERI: Earthquake Engineering Research Institute. EERI is a national nonprofit, interdisciplinary society devoted to the advancement of the science and practice of earthquake engineering in order to improve protection from and preparation for the effects of earthquakes. Among many publications, EERI has compiled a list of sources for earthquake information in the U.S. as part of their Earthquake Basics series.

FEMA: Federal Emergency Management Agency. The primary mission of FEMA is to protect lives and reduce property loss from natural disasters and other emergencies. FEMA acts as the focal point for all levels of government to develop a national emergency management capability that can deal effectively with any emergency. FEMA funds development of educational material and source documents for codes, including a series of publications with distinctive yellow covers.

Report to the Governor on the Northridge Earthquake: The report prepared by California's Seismic Safety Commission in response to an executive order by Governor Pete Wilson 
following the Northridge earthquake. The report, entitled Turning Loss to Gain, recommends policy improvements in the areas of geotechnical issues, building design and construction, land use planning and protection of lifelines.

Credits:

Seismic Safety Commission: P. Fratessa, J. Slosson, W. Iwan, A. Alquist, D. Cortese, G. McGavin, N. Becker, P. Snyder, H. Bernson, F. Herman, F. Winslow, J. Johnson, R. Wirtz, L. Cluff, J. Chang, C. Lee;

Executive Director T. Tobin;

Project Director: B. Norton:

Consultants: K. Coppersmith, J. Mintier, R. Reitherman, J. Penzien, W. Holmes.

ICSSC: Interagency Committee on Seismic Safety in Construction. A committee representing approximately 30 Federal departments and independent agencies involved in construction. The purpose is to coordinate efforts and to assist the departments and agencies in developing and incorporating earthquake hazard reduction measures in their ongoing programs.

IBC: The International Building Code. This new national model code will first be published in 2000 . The International Code Conference (ICC), made up of ICBO, the SBCCI, and BOCA, will develop the new code using existing standards and portions of the three currently existing model codes. The IBC will replace the UBC, the SBC, and the National Code. It is likely that the seismic provisions of the IBC will be based on the NEHRP Provisions.

NCEER: National Center for Earthquake Engineering Research. A national center located at the State University of New York at Buffalo but utilizing the facilities of many universities around the country, funded by NSF and the State of New York. NCEER was established to expand and disseminate knowledge about earthquakes improve earthquake-resistant design and implement seismic hazard mitigation procedures. The emphasis is on structures in the eastern and central U.S. and lifelines throughout the country.

NEHRP: The National Earthquake Hazards Reduction Program. The joint program by the federal government to reduce losses from earthquakes. The four federal agencies primarily involved are FEMA, USGS, NSF, and NIST.

NEHRP Provisions: The BSSC publication, Recommended Provisions for the Development of Seismic Regulations for Buildings. Based on ATC 3-06, the Provisions were first published in 1985 and are updated by the BSSC every three years. The Provisions now form the basis for the seismic regulations in The Standard Building Code and The BOCA National Building Code and are the minimum standard for the design of all federal buildings.

NIBS: National Institute of Building Sciences. NIBS is a non-profit, non-governmental organization bringing together representatives of government, private industry, labour, and consumer interests. The Institute's mission is to improve the building regulatory environment, facilitate the introduction of new and existing products and technology into the building process, and disseminate nationally recognized technical and regulatory information.

NIBS National Earthquake Loss Methodology: The product of the current project funded by FEMA through NIBS to develop a standardized method to estimate regional earthquake losses that could be applied anywhere in the U.S. . The method has been transformed into an elaborate GIS-based computer program called HAZUS. The project is scheduled for completion in late 1996.

Credits:

FEMA Project Manager: F. Sharrocks; NIBS Director: P. Schneider;

Project Working Group: R. Whitman (Chair), R. Borcherdt, D. Brookshire, R. Eisner, W. Holmes, R. Olson, M. O'Rourke, R. Reitherman;

Development Subcontractor: Risk Management Solutions, S. Lawson, C. Kircher.

NIST: National Institute of Standards and Technology. NIST is assigned the responsibility for carrying out research and development to improve building codes and standards and practices for structures and lifelines.

NSF: National Science Foundation. NSF supports research and related activities in the earthquake and natural hazards fields. A major funder of basic research in the U.S.

Project 97: A joint effort of BSSC and USGS to provide a seismic design procedure for the 1997 NEHRP Provisions that will utilize new national seismic hazard mapping. USGS is currently developing a variety of new national ground motion maps featuring a range of spectral ordinates and several different probability levels; BSSC has created a committee, the Seismic Design Procedures Group (SDPG), to develop a seismic design procedure and/or "zone" map or maps intended to use this new hazard data. The product of the SDPG is scheduled to be folded into the normal updating process of the 97 NEHRP Provisions.

Credits:

Project Management Committee: A. Porush, C. Allen, G. Bell, W. Holmes, R. Wesson;

USGS: A. Frankel, C. Mueller, T. Barnhard, D. Perkins, E. Leyendecker, N. Dickman, S. Hanson; SDPC:

Chair: J. Hunt;

Members: R. Borcherdt, C. Crouse, J. Harris, J. Kimball, C. Kircher, E. Leyendecker, G. Nordenson, T. Perbix, C. Poland, L. Reaveley, T. Sabol, R. Sharpe, J. Theiss, L. Wyllie.

Proposition 122: California State Proposition 122 passed in 1990 following the Loma Prieta earthquake. In addition to providing significant bond money for seismic strengthening of state buildings, the measure provided R/D funds to be overseen by the California Seismic Safety Commission. Among other projects, code-like seismic evaluation and strengthening provisions are being developed, specifically for older, non-ductile concrete buildings. The current draft provisions are similar to ATC 33 and contain several seismic performance levels.

SAC: An acronym for the joint venture of SEAOC, ATC, and CUREe. This Joint Venture was formed after the Northridge earthquake to develop new standards for the evaluation, repair, and retrofit of existing steel welded moment frames, and the design of new ones. Phase I of the investigation was completed in late 1995, resulting in Interim Guidelines, and Phase 2 is scheduled for completion in 1998.

SEAOC: The Structural Engineers Association of California. A professional association composed primarily of structural 
engineers practising in California, but also including, as associated members, civil and geotechnical engineers, as well as industry representatives from California as well as other states. Since 1958, the Seismology Committee of SEAOC has produced, with no outside funding, the Recommended Seismic Provisions for Buildings, commonly known as the Bluebook. The seismic provisions of the UBC have been based on the Bluebook recommendations.

Seismic Safety Commission: A California commission, with membership appointed by the governor, charged with improving the well being of the people of California through cost-effective measures which lower earthquake risks to life and property.

USGS: United States Geological Survey. USGS, a bureau of the Department of Interior, was established to provide a permanent Federal agency to conduct the systematic and scientific "classification of the public lands and examination of the geologic structure, mineral resources, and products of the national domain." USGS is the world's largest earth science research and information agency. Among its many duties is provision of national seismic hazard mapping.

Vision 2000: A SEAOC project to develop a next-generation seismic code. The initial phase has been funded by the California Office of Emergency Services. Initial conclusions included recommendations to develop reliable performance based design and an emphasis on seismic protection considerations from schematic design to lifelong building maintenance. SEAOC plans to continue the development of this concept as funds become available.

Credits:

Chair: C. Poland;

Members: J. Hill, R. Sharpe, V. Bertero, R. Chittenden, A. Court, R. Hamburger, J. Nicoletti, R. Phillips, N Youssef, S. Stedman, A. Virdee, J. Anderson, R. Nelson, C. Thiel, V. Mujumdar, R. Thacker, R Bachman, R. Fallgren.

\section{REFERENCES}

1. Seismic Safety Commission, 1994. A Compendium of Background Reports on the Northridge Earthquake, prepared under Executive Order W-78-94, California Seismic Safety Commission.

2. Seismic Safety Commission, 1995. The Northridge Earthquake: Turning Loss To Gain, prepared under Executive Order W-78-94, California Seismic Safety Commission.

3. BSSC, 1994. NEHRP Recommended Provisions for the Development of Seismic Regulations for New Buildings, Building Seismic Safety Council for the Federal Emergency Management Agency, Washington, D.C., USA.

4. Applied Technology Council. 1978 (second printing 1984). Tentative Provisions for the Development of Seismic Regulations for Buildings, ATC 3-06, Applied Technology Council, Redwood City, Calif., USA.

5. Applied Technology Council, 1985. Earthquake damage evaluation data for California, ATC-13, Applied Technology Council, Redwood City, Calif.,USA.

6. Freeman, Sigmund A., 1994, Capacity Spectrum Method, SEAONC 1994 Fall Seminar, The Developing Art of Seismic
Engineering, Structural Engineers Association of Northern California, San Francisco, Calif., USA.

7. Risk Management Software,1995, Draft Technical Manual for Development of a Standardized Earthquake Loss Estimation Methodology, National Institute of Building Sciences, Washington, D.C., USA.

8. Morelli, U. and C. Rojahn, 1993. Seismic Rehabilitation of Buildings: the FEMA Program, in Earthquake hazard reduction in the central and eastern United States: a time for examination and action, Proceedings of the 1993 National Earthquake Conference, Memphis, Tenn., 2:5-14, Central United States Earthquake Consortium, Memphis, Tenn., USA.

9. Applied Technology Council, 1995. Guidelines for the Seismic Rehabilitation of Buildings and Commentary, $75 \%$ complete draft; ATC 33.03. 3 vols, prepared for the Building Seismic Safety Council with funding from the Federal Emergency Management Agency, Applied Technology Council, Redwood City, Calif., USA.

10. Hamburger, Ronald O., 1996. Performance Based Guidelines for Seismic Rehabilitation of Buildings, paper submitted to International Conference on Retrofitting of Structures, Columbia University, New York City, USA.

11. BSSC, 1992. NEHRP Handbook for the Seismic Evaluation of Existing Buildings, FEMA-178, Building Seismic Safety Council, Washington, D.C., USA.

12. Structural Engineers Association of California, 1995. Performance Based Seismic Engineering of Buildings, Vision 2000 Committee, SEAOC, Sacramento, Calif., USA.

13. Seismic Safety Commission, 1995. Recommended Methodology for Seismic Evaluation and Retrofit of Existing Buildings, Second Draft, prepared by Applied Technology Council, Redwood City, Calif., USA.

14. Interagency Committee on Seismic Safety in Construction, 1992. Guidelines and Procedures for Implementation of Executive Order on Seismic Safety of New Building Construction, ICSSC RP 2.1a, NISTIR 4852, National Institute of Standards and Technology, Gaithersburg, MD, October 1995.

15. Interagency Committee on Seismic Safety in Construction 1994. Standards of Seismic Safety for Existing Federally Owned or Leased Buildings, NISTIR 5382, ICSSC RP 4, D. Todd, editor, National Institute of Standards and Technology, Gaithersburg, MD, USA

16. Interagency Committee on Seismic Safety in Construction 1994. ICSSC Guidance on Implementing Executive Order 12941 on Seismic Safety of Existing Federally Owned or Leased Buildings, NISTIR 5734, ICSSC RP 5, D. Todd and A. Bieniawski editors, National Institute of Standards and Technology, Gaithersburg, MD, USA, October 1995.

17. Structural Engineers Association of Southern California, 1994. Findings \& Recommendations of the City of Los Angeles/SEAOSC Task Force on the Northridge Earthquake, November 12, 1994 Seminar Notes, Structural Engineers Association of Southern California. 